\title{
Determination of Plasma Tenofovir Concentrations Using a Conventional LC-MS Method
}

\author{
Masaaki TAKahashi, ${ }^{a, b}$ Yuichi KUdAKa, ${ }^{a}$ Naoya OKumura, ${ }^{a, b}$ Atsushi HiRano, ${ }^{a, b}$ \\ Kazuhide BANNO, ${ }^{a}$ and Tsuguhiro KANEDA* ${ }^{*} b$ \\ ${ }^{a}$ Department of Pharmacy, National Hospital Organization Nagoya Medical Center (Tokai Area Central Hospital for AIDS \\ Treatment and Research); and ${ }^{b}$ Clinical Research Center, National Hospital Organization Nagoya Medical Center (Tokai \\ Area Central Hospital for AIDS Treatment and Research); 4-1-1 Sannomaru, Naka-ku, Nagoya, Aichi 460-0001, Japan. \\ Received April 3, 2007; accepted July 3, 2007; published online July 6, 2007
}

\begin{abstract}
The quantification of tenofovir, a nucleoside reverse transcriptase inhibitor prescribed once daily, in human plasma is important due to a recent increase in its use. HPLC, however, can not easily detect and quantify tenofovir because of interfering peaks. Therefore, we developed a rapid and conventional LC-MS method, validated by estimating the precision and accuracy for inter- and intraday analysis in the concentration range of 0.019$1.567 \mu \mathrm{g} / \mathrm{ml}$. The calibration curve was linear in the described concentration range. Average accuracy ranged from 95.9 to $100.7 \%$. Relative standard deviations of both inter- and intraday assays were less than $11.6 \%$. Recovery of tenofovir was more than $\mathbf{8 0 . 2} \%$. This novel method provides a conventional, accurate and precise way to determine tenofovir in human plasma samples.
\end{abstract}

Key words human immunodeficiency virus (HIV)-1; LC-MS; therapeutic drug monitoring; tenofovir

Tenofovir is one of the nucleoside reverse transcriptase inhibitors used to treat human immunodeficiency virus (HIV)1. Tenofovir can be administered once-daily at a dose of $300 \mathrm{mg}$ in combination with other antiretroviral drugs. ${ }^{1,2)}$ The advantage of once-daily dosing is a reduction in patient drug load. Also, tenofovir appeared to be well tolerated with low rates of drug-related therapy discontinuation in several clinical trials. ${ }^{3,4}$ Thus, tenofovir use is expected to increase. However, some drug interactions with tenofovir and coadministered drugs have been reported. ${ }^{4-7)}$ Furthermore, tenofovir has been associated with renal impairment. ${ }^{8-10)}$

Recently, several determination methods for plasma tenofovir using high-performance liquid chromatography $(\text { HPLC })^{11-13)}$ or liquid chromatography-tandem mass spectrometry (LC-MS-MS), ${ }^{14,15)}$ have been reported. HPLC methods, however, are procedurally complicated, such as solid-phase drug extraction and derivatization with chloroacetaldehyde. Also, when using the LC-MS-MS method the MS-MS detector needs to be delicately set. In addition, LCMS-MS equipment is very expensive. We aimed, therefore, to develop a conventional procedure for determining tenofovir using liquid chromatography coupled with mass spectrometry (LC-MS).

\section{MATERIALS AND METHODS}

Chemicals and Reagents Tenofovir was supplied by Gilead Sciences (Foster City, CA, U.S.A.). The internal standard, atenolol, was purchased from Sigma-Aldrich (St. Louis, MO, U.S.A.). Acetonitrile (Kanto Chemical, Tokyo, Japan) was HPLC grade. Water was deionized and osmosed using a Milli- $Q^{\circledR}$ system (Millipore Corp., Bedford, MA, U.S.A.). All other chemicals and solvents were of analytical grade.

Equipment A Waters Alliance 2695 HPLC and a Micromass ZQ-2000 MS (Waters Assoc., Milford, MA, U.S.A.), controlled with MassLynx version 4.0 software, were used for detection. The analytical column was a SunFire $\mathrm{C}_{18}$ col- umn $(3.5 \mu \mathrm{m}, 2.1 \times 50 \mathrm{~mm}$, Waters $)$, protected by a SunFire $\mathrm{C}_{18}$ Guard Column.

Chromatographic and Mass Spectrometric Conditions The mobile phase was a mixture of $0.3 \%$ trifluoroacetic acid (A), $100 \%$ acetonitrile (B) and $100 \mathrm{~mm}$ ammonium acetate (C). An isocratic mobile phase consisting of $\mathrm{A}-\mathrm{B}-\mathrm{C}$ $(95: 0: 5)$ was used during the first $3 \mathrm{~min}$ of the run, followed by a linear gradient elution consisting of A-B-C $(45: 50: 5)$ for the next $5 \mathrm{~min}$. Then, the system was reequilibrated for an additional $12 \mathrm{~min}$ using the initial conditions. The flow rate of the mobile phase was $0.2 \mathrm{ml} / \mathrm{min}$, the column temperature was $40^{\circ} \mathrm{C}$ and the amount of injected sample was $5 \mu \mathrm{l}$.

The mass spectrometer was operated in positive ion electrospray mode. The capillary sprayer voltage was $3.5 \mathrm{kV}$ and the sample cone voltage was $30 \mathrm{~V}$ for both tenofovir and atenolol. The source temperature was $120^{\circ} \mathrm{C}$ and the desolvation temperature was $350^{\circ} \mathrm{C}$. The desolvation and cone gas flow-rates were set to 600 and $50 \mathrm{l} / \mathrm{h}$, respectively. The acquisition mass range is $m / z 100-700$ at $0.5 \mathrm{~s}$ per scan with a $0.1 \mathrm{~s}$ interscan delay. All mass spectra are acquired in centroid mode.

Quantitative analysis, carried out in Selected-ion recording (SIR) mode, detected tenofovir at $\mathrm{m} / \mathrm{z} 288$, and the internal standard (IS), atenolol, at $\mathrm{m} / \mathrm{z} 267$, all in the form of ions. The quantitation calculations were performed using analytical software, MassLynx version 4.0 (Waters).

Standard Solutions Stock solutions of tenofovir and atenolol were prepared by dissolving accurately weighed amounts of each reference compound in water/ethanol $(50: 50, \mathrm{v} / \mathrm{v})$ to yield concentrations of $188.0 \mu \mathrm{g} / \mathrm{ml}$ for tenofovir, and $48.1 \mu \mathrm{g} / \mathrm{ml}$ for atenolol. These stock solutions were stored at $-80^{\circ} \mathrm{C}$ and thawed on the day of analysis. The stock solution was diluted in drug-free plasma to yield tenofovir concentrations of $0.019,0.094,0.313,0.940$ and $1.567 \mu \mathrm{g} / \mathrm{ml}$.

Sample Preparation Twenty microliters of IS solution (atenolol $48.1 \mu \mathrm{g} / \mathrm{ml}$ ) and $200 \mu \mathrm{l}$ of $1 \mathrm{~N} \mathrm{HCl}$ were added to a $500 \mu \mathrm{l}$ plasma sample prepared from peripheral blood antico- 
agulated with heparin. After vortexing briefly, $2 \mathrm{ml}$ of $100 \%$ acetnitrile was added to the mixture. The mixture was vortexed again and then centrifuged at $3500 \boldsymbol{g}$ for $5 \mathrm{~min}$. The upper layer was separated and evaporated dry. The dried material was then dissolved in $100 \mu$ l of a mobile phase solution and centrifuged at $13000 \boldsymbol{g}$ for $5 \mathrm{~min}$. Lastly, $5 \mu \mathrm{l}$ of the upper solution was injected into the LC-MS system. The institutional review board of National Hospital Organization Nagoya Medical Center approved this study and each subject provided written informed consent.

Validation Inter- and intraday precision values using this method were estimated by assaying control plasma containing five different concentrations of tenofovir five times on the same day and on three separate days to obtain the relative standard deviation (RSD). Accuracy was determined as the percentage of the nominal concentration. To assess the absolute recoveries of tenofovir extracted from plasma, the peak area ratios of the analytes to the internal standard were compared with those obtained from the mobile phase having the same concentration. The mean recoveries were determined in three replicates.

\section{RESULTS}

LC-MS Chromatograms Figures $1 \mathrm{~A}$ and $\mathrm{B}$ show selected-ion recording chromatograms obtained from a spiked plasma sample containing $0.94 \mu \mathrm{g} / \mathrm{ml}$ of tenofovir and $1.85 \mu \mathrm{g} / \mathrm{ml}$ of atenolol (IS). Under the described chromatographic conditions, retention times were $4.4 \mathrm{~min}$ for tenofovir and $9.9 \mathrm{~min}$ for atenolol. Figures $1 \mathrm{C}$ and $\mathrm{D}$ show chromatograms obtained from a blank plasma sample. Assays performed on drug-free human plasma succeeded to show no interfering peaks during the interested intervals of the retention times. Figure 1D is the expanded figure of a circled part of Fig. 1B. These peaks did not affect on the quantification of IS. Figures $1 \mathrm{E}$ and $\mathrm{F}$ show chromatogram of a plasma sample from an HIV-1-infected patient treated with tenofovir. There were no interfering peaks affecting quantification of tenofovir in this chromatogram. Anticoagulants of heparin, EDTA and ACD did not hinder the selected-ion recording chromatograms for tenofovir and atenolol.

Validation: Linearity, Precision, Accuracy and Recovery Calibration curves of tenofovir appeared linear in the concentration range of 0.019 to $1.567 \mu \mathrm{g} / \mathrm{ml}$ with a correlation of 1.000 .

Precision, accuracy, and recovery of our LC-MS method are shown in Table 1. The selected concentration of tenofovir covers the expected plasma concentrations found in the patients. The RSDs calculated for tenofovir in the inter- and intraday assays ranged from 1.5 to $11.3 \%$, which are similar to or much lower than previously reported values. ${ }^{11-16)}$ Accuracies ranged from 95.9 to $102.7 \%$. Recoveries from plasma

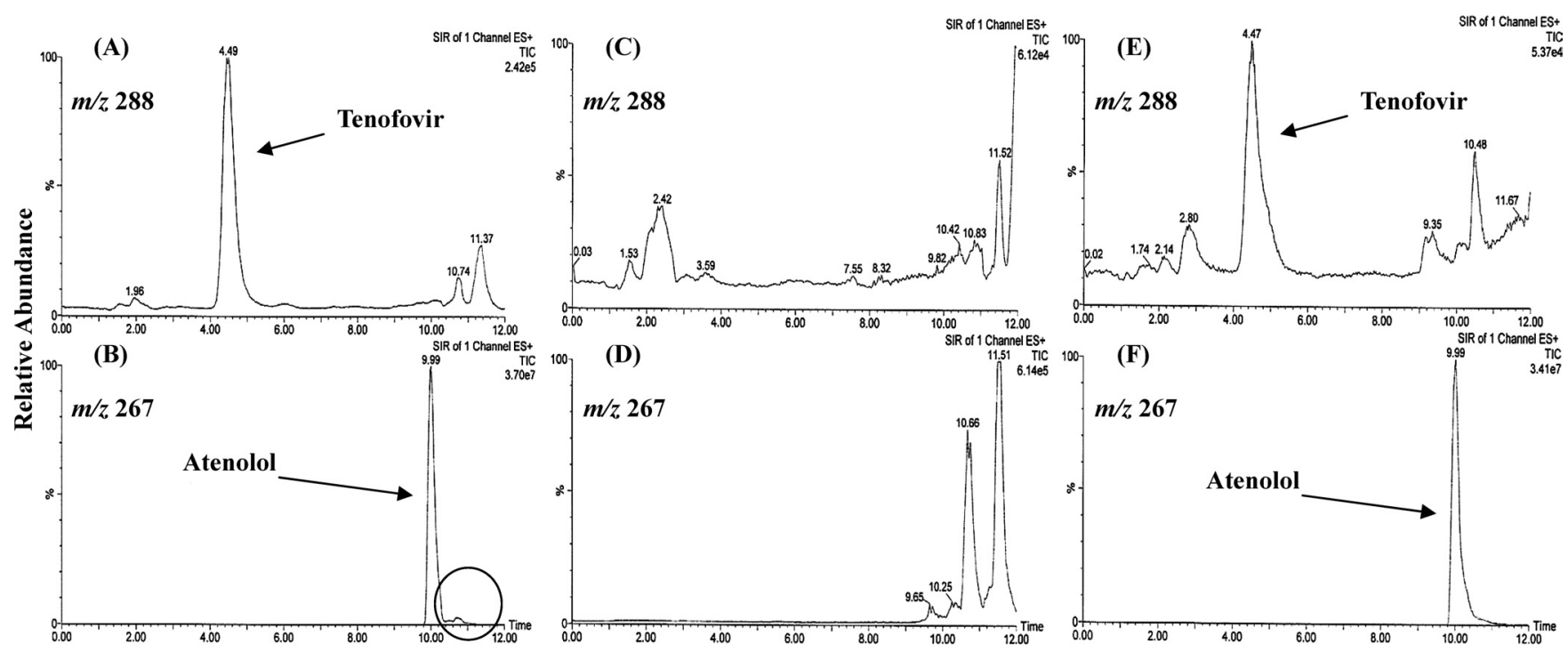

Fig. 1. Selected-Ion Recording Chromatograms for Tenofovir and Atenolol

(A) and (B) were obtained from a spiked plasma containing $0.94 \mu \mathrm{g} / \mathrm{ml}$ of tenofovir and $1.85 \mu \mathrm{g} / \mathrm{ml}$ of atenolol (IS). (C) and (D) were obtained from a blank plasma sample. (E) and (F) were obtained from a plasma sample from an HIV-1-infected patient with tenofovir. (A), (C) and (E) were monitored with $m / z 288$. (B), (D) and (F) were monitored with $m / z$ 267. (D) is the expanded figure of a circled part of (B).

Table 1. Intraday and Interday Precision and Accuracy for Tenofovir

\begin{tabular}{|c|c|c|c|c|c|c|}
\hline \multirow{2}{*}{ Expected $(\mu \mathrm{g} / \mathrm{ml})$} & \multicolumn{2}{|c|}{ Intraday $(n=5)$} & \multicolumn{2}{|c|}{ Interday $(n=3)$} & \multirow{2}{*}{ Accuracy $(\%)$} & \multirow{2}{*}{ Recovery (\%) } \\
\hline & Measured $(\mu \mathrm{g} / \mathrm{ml})$ & RSD (\%) & Measured $(\mu \mathrm{g} / \mathrm{ml})$ & RSD (\%) & & \\
\hline 0.019 & $0.019 \pm 0.002$ & 10.0 & $0.020 \pm 0.002$ & 11.3 & $102.7 \pm 11.6$ & $80.2 \pm 9.4$ \\
\hline 0.094 & $0.095 \pm 0.007$ & 7.4 & $0.092 \pm 0.005$ & 5.7 & $98.2 \pm 5.7$ & $95.2 \pm 10.4$ \\
\hline 0.313 & $0.313 \pm 0.012$ & 4.0 & $0.300 \pm 0.016$ & 5.2 & $95.9 \pm 5.0$ & $92.2 \pm 10.4$ \\
\hline 0.940 & $0.921 \pm 0.039$ & 4.3 & $0.931 \pm 0.054$ & 5.8 & $99.1 \pm 5.7$ & $86.1 \pm 7.4$ \\
\hline 1.567 & $1.570 \pm 0.024$ & 1.5 & $1.578 \pm 0.045$ & 2.8 & $100.7 \pm 2.9$ & $91.1 \pm 6.2$ \\
\hline
\end{tabular}

RSD, relative standard deviation. 
Table 2. Plasma Tenofovir Concentrations after the Oral Administration of $300 \mathrm{mg}$ of Tenofovir to an HIV-1-Infected Patient

\begin{tabular}{cc}
\hline \hline Time $(\mathrm{h})$ & Tenofovir concentration $(\mu \mathrm{g} / \mathrm{ml})$ \\
\hline 0 & 0.073 \\
4 & 0.316 \\
6 & 0.162 \\
12 & 0.106 \\
23 & 0.052 \\
\hline
\end{tabular}

ranged from 80.2 to $95.2 \%$. These results indicate this method achieves a high degree of reproducibility and accuracy.

Tenofovir Concentrations in Plasma Plasma tenofovir concentrations in an HIV-1-infected patient are shown in Table 2. The patient received oral administration of $300 \mathrm{mg}$ tenofovir daily. These concentrations were similar to those reported previously. ${ }^{11,12,17)}$

\section{DISCUSSION}

Prior to this study we tried to determine tenofovir plasma concentrations using a previously described HPLC method. ${ }^{12)}$ However, we could not identify and quantify tenofovir peaks on chromatograms of plasma sample due to interfering peaks. Thus, we developed a more sensitive method. Until now there have been some methodological reports for the determination of tenofovir using LC-MS-MS. ${ }^{14,15)}$ However, these methods have several disadvantages in terms of cost performance, time consumption and essential equipment; for example, the authors used expensive disposable cartridges at the solid-phase drug extraction and/or the setting of the LCMS-MS equipment.

To avoid such disadvantages we decided to use a LC-MS method. Validation showed our method was successful in measuring plasma tenofovir with high precision and satisfactory RSD values. The tenofovir calibration curve was linear in the concentration range of 0.019 to $1.567 \mu \mathrm{g} / \mathrm{ml}$ and the average accuracy ranged from 95.9 to $100.7 \%$. Both interand intraday RSDs for tenofovir were less than $11.6 \%$, which is similar to or much lower than previously reported values. $^{11-16)}$ Recovery of tenofovir was more than $80.2 \%$. These results indicate our newly developed method achieves a high degree of reproducibility and accuracy. As plasma concentrations of tenofovir are expected in the 0.05 to $0.40 \mu \mathrm{g} / \mathrm{ml}$ range when tenofovir is administered at the recommended dose, ${ }^{4,17)}$ our method successfully covers this region with good precision and accuracy. Actually, plasma tenofovir concentrations after oral administration of $300 \mathrm{mg}$ to an HIV-1infected patient were in this range.

This conventional LC-MS method can provide a routine clinical application, and permits management of drug interactions and toxicity.

Acknowledgements This study was supported in part by a Health Science Research Grant for Research on HIV/AIDS from the Ministry of Health, Labor, and Welfare of Japan (H13-AIDS-001 and H16-AIDS-002 to TK).

\section{REFERENCES}

1) Fung H. B., Stone E. A., Piacenti F. J., Clin. Ther., 24, 1515-1548 (2002).

2) Kumar A., Drugs, 63, 1597-1608 (2003).

3) Barditch-Crovo P., Deeks S. G., Collier A., Safrin S., Coakley D. F., Miller M., Kearney B. P., Coleman R. L., Lamy P. D., Kahn J. O., McGowan I., Lietman P. S., Antimicrob. Agents Chemother, 45, 2733 2739 (2001).

4) Product information, VIREAD ${ }^{\circledR}$ (tenofovir disoproxil fumarates), Foster City, CA: Giread Sciences, 2006.

5) Droste J. A., Kearney B. P., Hekster Y. A., Burger D. M., J. Acquir. Immune Defic. Syndr., 41, 37-43 (2006).

6) Kearney B. P., Sayre J. R., Flaherty J. F., Chen S. S., Kaul S., Cheng A. K., J. Clin. Pharmacol., 45, 1360-1367 (2005).

7) Taburet A. M., Piketty C., Chazallon C., Vincent I., Gerard L., Calvez V., Clavel F., Aboulker J. P., Girard P. M., Antimicrob. Agents Chemother., 48, 2091-2096 (2004).

8) Zimmermann A. E., Pizzoferrato T., Bedford J., Morris A., Hoffman R., Braden G., Clin. Infect. Dis., 42, 283-290 (2006).

9) Murphy M. D., O’Hearn M., Chou S., Clin. Infect. Dis., 36, 10821085 (2003).

10) Winston J. A., Shepp D. H., Clin. Infect. Dis., 42, 1657-1658 (2006).

11) Sparidans R. W., Crommentuyn K. M. L., Schellens J. H. M., Beijnen J. H., J. Chromatogr. B, 791, 227-233 (2003).

12) Sentenac S., Fernandez C., Thuillier A., Lechat P., Aymard G., J. Chromatogr. B, 793, 317-324 (2003).

13) Jullien V., Treluyer J.-M., Pons G., Rey E., J. Chromatogr. B, 785, 377-381 (2003).

14) Delahunty T., Bushman L., Fletcher C. V., J. Chromatogr. B, 830, 6 12 (2006).

15) Bezy V., Morin P., Couerbe P., Leleu G., Agrofoglio L., J. Chromatogr. $B, \mathbf{8 2 1}, 132-143$ (2005).

16) Rezk N. L., Crutchley R. D., Kashuba A. D. M., J. Chromatogr. B, 822, 201-208 (2005).

17) Droste J. A. H., Verweij-van Wissen C. P. W. G. M., Kearney B. P., Buffels R., van Horssen P. J., Hekster Y. A., Burger D. M., Antimicrob. Agents Chemother, 49, 680-684 (2005). 